\title{
Effects of Asphyxia on Renal Function in the Newborn Piglet
}

\author{
CHARLES T. ALWARD, JERRY B. HOOK, THOMAS A. HELMRATH, AND MICHAEL D. \\ BAILIE $^{(22)}$ \\ Departments of Human Development, Physiology, and Pharmacology, Michigan State University, East Lansing, \\ Michigan, USA
}

\begin{abstract}
Summary
This investigation was undertaken to determine the nature of acute alterations in renal function following the production of hypoxemia, hypercarbia, and acidosis in newborn piglets 6-96 hr of age. After completion of the surgical procedure piglets were allowed to recover from the effects of anesthesia. When respiratory dead space was increased arterial oxygen tension decreased whereas arterial carbon dioxide tension and hydrogen ion concentration increased. There was little change in glomerular filtration rate. Total renal blood flow decreased and renal vascular resistance increased significantly $(504 \pm 78 \mathrm{~mm} \mathrm{Hg} /$ liter $/ \mathrm{mm} / \mathrm{m}^{2}$ to $\left.1422 \pm 504\right)$. There was no change in distribution of intrarenal blood flow. Sodium excretion and urinary flow rate demonstrated significant parallel increases following the increase in dead space. Plasma renin concentration increased from 67 to $110 \mathrm{ng} / \mathrm{ml}$.
\end{abstract}

\section{Speculation}

Hypoxia, hypercarbia, and acidosis produced changes in renal function in newborn piglets. Therapeutic approaches to the newborn human with respiratory distress must consider the potential for modifications of renal function which may be detrimental to the infant.

The effects of respiratory distress on cardiopulmonary function in the newborn infant have been extensively studied. However, renal function during this disease process has not been adequately described. Recent observations have indicated that newborn infants with respiratory distress become oliguric $(4,19)$, have defects in renal acidification $(1,19)$, and have diminished inulin and $p$-aminohippurate clearances (9). However, studies performed on human infants with respiratory distress may be subject to the effects of mechanical ventilatory support (12) as well as influences of relative states of hydration, temperature, nutrition, and drug therapy. The present investigation was undertaken to determine the nature of acute alterations in renal function following the production of hypoxemia, hypercarbia, and acidosis in . unanesthetized. newborn piglets. without ventilatory support.

\section{MATERIALS AND METHODS}

Experiments were performed on 15 crossbred piglets obtained from the Swine Research Farm at Michigan State Univeristy. The piglets were born by spontaneous vaginal delivery and were studied between 6 and $96 \mathrm{hr}$ of age. At the time of the study they weighed between $1020 \mathrm{~g}$ and $2180 \mathrm{~g}$.

Surgical procedures were performed under combined anesthesia with nitrous oxide-oxygen $(4: 1)$ and ketamine $(5 \mathrm{mg} / \mathrm{kg} \mathrm{im})$. A polyethylene catheter (PE-50) was inserted into the right femoral vein for infusion of $\left[{ }^{3} \mathrm{H}\right]$ methoxyinulin. A second cath- eter was advanced into the abdominal aorta from the right femoral artery. This catheter was used for the determination of blood pressure and heart rate and for sampling arterial blood. Radioactive microsphere injections were made through a third catheter (PE-90) placed in the ascending aorta by way of the left carotid artery. The urinary bladder was isolated through a small midline abdominal incision and catheterized directly. The position of all catheters was confirmed by inspection at the end of the experiment.

After suturing the skin incisions all wounds were infiltrated with lidocaine. Anesthesia was discontinued and the piglets were placed upright in a supporting sling and allowed to recover from anesthesia for $1 \mathrm{hr}$. During the surgical procedure and the experiment the piglets were maintained at a body temperature of $38^{\circ}$ using a Merco infant warmer. Under these conditions the animals remained calm and undisturbed in the sling, often sleeping during the experiment. Rectal temperature was continuously monitored using a Yellow Springs thermister. After completion of the surgical procedure the piglets were intubated with a $3.5 \mathrm{~mm}$ Portex endotracheal tube. Baseline determinations were made and then a dead space (approximately $45 \mathrm{cc} /$ $\mathrm{kg}$ ) was added to the endotracheal tube in order to produce hypoxia and hypercarbia.

Tritiated methoxy inulin $(1 \mu \mathrm{Ci} / \mathrm{ml})$ was infused into the femoral vein at a rate of $0.04 \mathrm{ml} / \mathrm{min}$ beginning $1 \mathrm{hr}$ before the onset of the experiment. During each clearance period urine collections were made in preweighed flasks under oil. Urine flow rate was estimated from the change in weight without correction for specific gravity. Urine was collected for determination of inulin and sodium and potassium concentration. Arterial blood samples for determination of inulin, sodium and potassium, hematocrit, and plasma renin activity were obtained midway through each 20 -min clearnace period. The blood samples were centrifuged immediately, the plasma removed, and the cells reconstituted in saline and returned to the animal. Failure to show any physiologically significant changes in hematocrit suggested that blood volume was unchanged. Blood samples for plasma renin activity were collected in chilled tubes containing disodium ethylenediaminetetraacetic acid.

Heart rate and blood pressure were monitored continuously using a Statham pressure transducer $(\mathrm{P} 23 \mathrm{~dB})$ and recorded on a Grass Instruments polygraph. Respiratory rate was determined by direct observation twice during each clearnace period. Arterial $\mathrm{pO}_{2}, \mathrm{pCO}_{2}$, and $\mathrm{pH}$ were measured using a Radiometer blood gas analyzer (model BMS 3 ). $\mathrm{pH}$ values were converted to hydrogen ion concentration for statistical analysis.

Renal blood flow was determined using $15-\mu \mathrm{m}$ microspheres (3M Company) labeled with ${ }^{51} \mathrm{Cr},{ }^{85} \mathrm{Sr}$, or ${ }^{141} \mathrm{Ce}$. The microspheres were agitated thoroughly in $0.5 \mathrm{ml} 20 \%$ dextran solution and injected rapidly into the carotid catheter. During injection blood was removed for $1 \mathrm{~min}$ at a constant rate of $1.45 \mathrm{ml} / \mathrm{min}$ from the femoral artery catheter using a Harvard infusion/ withdrawal pump. This blood sample served as the standard 
flow rate for comparison with measured organs. Saline was infused to replace this blood loss. Additional injections were made during the course of the experiment with the order of the labeled microspheres being randomly varied. Next the kidneys were removed, weighed, and placed in counting tubes. A sample of the cortex from each kidney was divided in half (outer and inner cortical portions) to measure the outer to inner cortical flow ratio. The amount of radioactivity per specimen was counted in a Searle 1185 series three-channel $\gamma$ counter.

The protocol for the experiments was as follows. Two 20-min clearance periods were followed by the first injection of labeled microspheres. These periods represented the control phase for each experiment. The dead space was then added to the endotracheal tube. After a 30-min stabilization period, a second microsphere injection was performed. Three clearance periods followed and then the third microsphere injection was made, 90 min after respiratory distress had been initiated. The dead space was removed and two more clearance periods were obtained, representing the recovery phase. The piglet was then killed by an intravenous injection of sodium pentobarbital.

Renal blood flow, was calculated from the following formula: flow (milliliters per min per $\mathrm{g}$ ) $=\mathrm{q} / \mathrm{wt} \times \mathrm{F} / \mathrm{Q}$ where $\mathrm{q}=$ counts per specimen; wt $=$ tissue weight in grams; $F=$ withdrawal rate into arterial sampling syringe in milliliters per min; $Q=$ total counts in arterial sampling syringe. Blood flow was expressed as milliliters per min per $\mathrm{m}^{2}$ surface area. Tritiated methoxyinulin was determined in plasma and urine by liquid scintillation counting with correction made for quenching. Glomerular filtration rate was estimated from the clearance of inulin. Renal resistance was calculated as the quotient of the mean blood pressure and renal blood flow and expressed as $\mathrm{mm} \mathrm{Hg}$ per liter per min per $\mathrm{m}^{2}$. The excretion of sodium was calculated and expressed as microequivalents per min. Plasma renin concentration was determined by adding $25 \mu \mathrm{l}$ plasma to excess homologous renin substrate and the angiotensin I formed after a 1-hr incubation was determined by radioimmunoassay (10). Renin activity was expressed as nanograms per $\mathrm{ml}$.

Data were analyzed using the Student $t$-test and analysis of variance with the least significant differences test. The 0.05 level of probability was used as the criterion of significance. All values are expressed as mean $\pm \mathrm{SE}$.

\section{RESULTS}

The experiments were divided into three phases: control, increased respiratory dead space, and recovery. Each of the 15 animals acted as its own control, permitting comparison of data from the experimental periods with the control and recovery periods. After the increase in respiratory dead space, arterial oxygen tension decreased whereas arterial carbon dioxide tension and hydrogen ion concentration increased (Fig. 1).

The changes in $\mathrm{PaO}_{2}, \mathrm{PaCO}_{2}$ and $\mathrm{pH}$ produced by increasing the dead space produced little change in glomerular filtration rate (Fig. 2). However, total renal blood flow decreased and remained low throughout the course of the experiment (Fig. 3). This decrease in renal blood flow was associated with a significant increase in renal vascular resistance from $504 \pm 78 \mathrm{~mm}$ $\mathrm{Hg} / \mathrm{liter} / \mathrm{min} / \mathrm{m}^{2}$ to $1422 \pm 504 \mathrm{~mm} \mathrm{Hg} / \mathrm{liter} / \mathrm{min} / \mathrm{m}^{2}$. There were only small and insignificant changes in outer cortical to inner cortical flow ratios during this time (Fig. 3).

Absolute sodium excretion and urinary flow rate demonstrated parallel increases following the increase in dead space (Fig. 4). These responses were delayed for approximately 45 min after the endotracheal tube was lengthened. Potassium excretion was unchanged.

Arterial plasma renin concentration (Fig. 5) was $67 \mathrm{ng} / \mathrm{ml}$ during the control periods. By the end of the experimental periods renin concentration had risen to $110 \mathrm{mg} / \mathrm{ml}$, and remained at that level during the recovery phase.

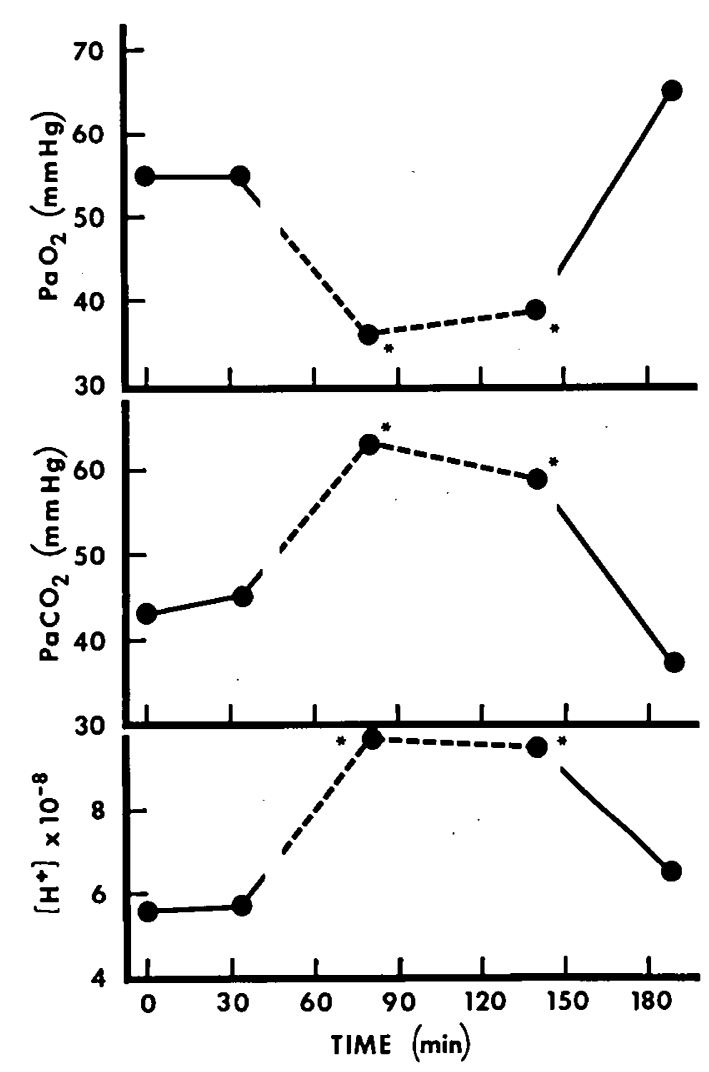

Fig. 1. Changes in arterial $\mathrm{PaO}_{2}, \mathrm{PaCO}_{2}$ and hydrogen ion concentration associated with changes in respiratory dead space. The period of increased dead space is shown by the dashed line. Asterisk $\left({ }^{*}\right)$ indicates values significantly different than control period $(P<0.05)$.

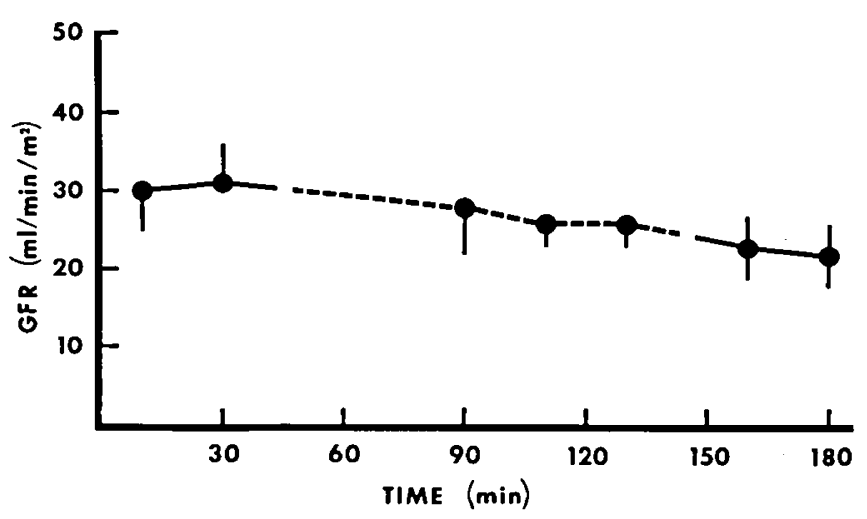

Fig. 2. Changes in glomerular filtration rate (GFR) in piglets following increased respiratory dead space. The period of increased dead space is shown by the dashed line.

\section{DISCUSSION}

Respiratory distress in the newborn period is frequently associated with hypoxia, hypercarbia and acidosis. Although cardiovascular and pulmonary function have been extensively studied during this period much less information is available concerning renal function. In the present experiments an increase in respiratory dead space was utilized to produce hypoxia, hypercarbia, and acidosis. Addition of the dead space resulted in a decrease in arterial $\mathrm{pO}_{2}$ and an increase in $\mathrm{pCO}_{2}$ and hydrogen ion concentration (Fig. 1). The situation described here does not precisely mimic the clinical state; nevertheless, the present studies do allow observations to be made on effects 


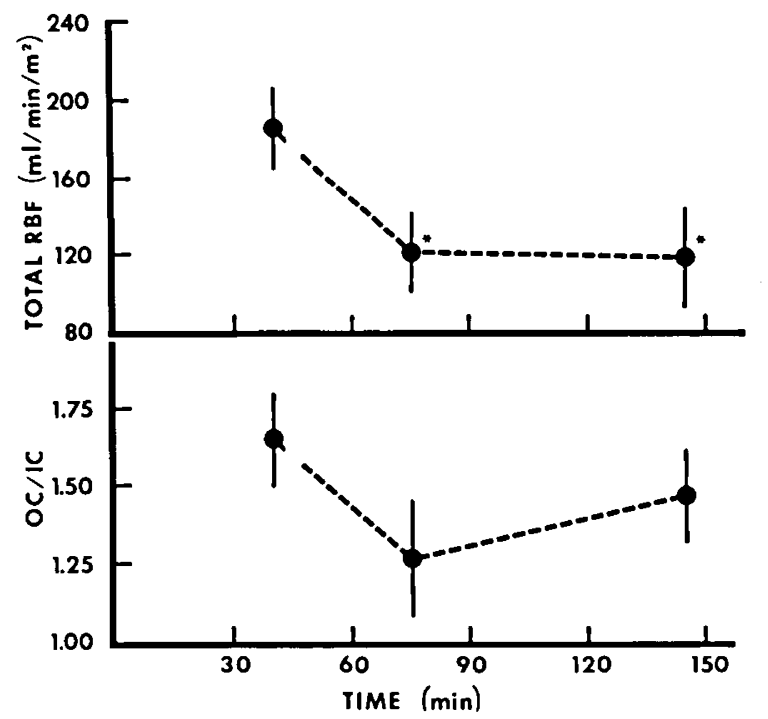

Fig. 3. Changes in total renal blood flow (RBF) and outer cortical to inner cortical ratio $(\mathrm{OC} / \mathrm{IC})$ in piglets after increased respiratory dead space. The period of increased dead space is shown by the dashed line. Asterisk (*) indicates values significantly different than control period $(P<0.05)$.

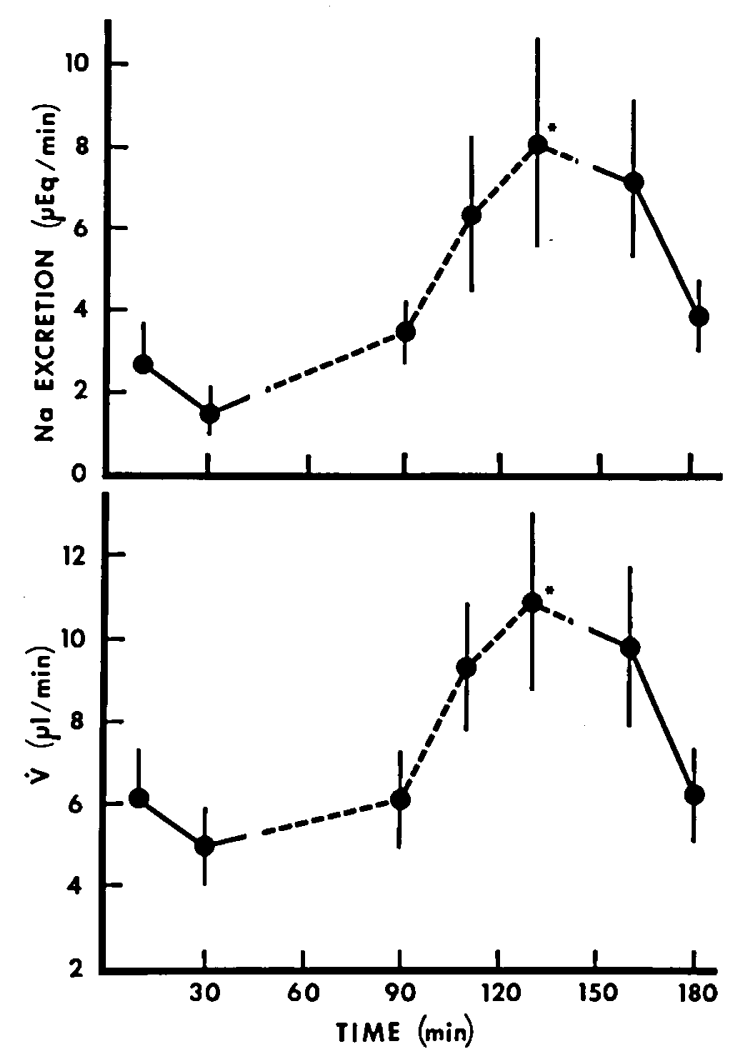

Fig. 4. Changes in sodium excretion and urinary flow rate $(\dot{V})$ in piglets following increased respiratory dead space. The period of increased dead space is shown by the dashed line. Asterisk (*) indicates values significantly different than control $(P<0.05)$.

of changes in composition of blood gases without the complicating factors associated with medical intervention and therapy.

The increase in respiratory dead space with resultant hypoxia, hypercarbia and acidosis is associated with several systemic hemodynamic changes. Heart rate, mean arterial blood pressure and respiratory rate increased (2). When the dead space was

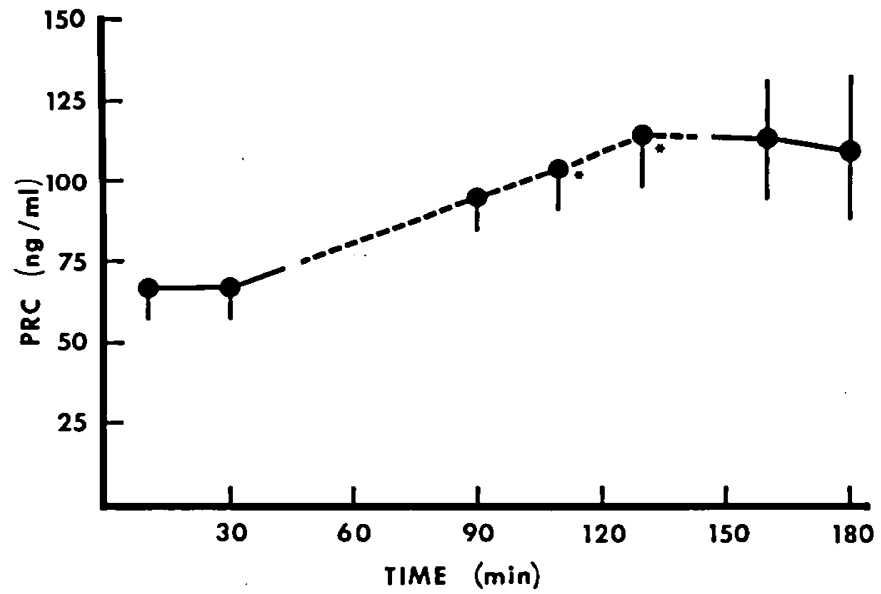

Fig. 5. Changes in plasma renin concentration (PRC) in piglets after increased respiratory dead space. Period of increased dead space is shown by the dashed line. Asterisk $\left(^{*}\right)$ indicates values significantly different than control $(P<0.05)$.

increased glomerular filtration rate did not change during the acute phase of respiratory distress (Fig. 2). In contrast, renal blood flow decreased (Fig. 3), suggesting that the increase in renal resistance was due to uniform changes in both afferent and efferent glomerular arteriolar tone. The constant filtration rate and decrease in blood flow would result in an increase in the filtration fraction. The failure to find any significant changes in the outer cortical to inner cortical flow ratio also suggests that the decrease in renal blood flow took place uniformly throughout the renal cortex.

Siegel et al. (16) reported no change in glomerular filtration rate in optimally managed infants with respiratory distress syndrome. On the other hand, Torrado and Guignard (19) reported a decrease in glomerular filtration rate and suggested that the difference may be due to the severity of respiratory distress as well as analytic techniques used (18). It is possible that in the present studies the glomerular filtration rate would have decreased had the experiment been carried out for a longer period of time.

The finding that the decrease in renal blood flow was not associated with a similar change in glomerular filtration rate suggests that glomerular filtration is not plasma flow dependent (3). This situation may represent a species variation, an age or developmental phenomenon, or possibly whole kidney glomerular filtration does not represent a true reflection of superficial cortical nephron filtration rate.

The induction of hypoxia, hypercarbia, and acidosis was followed by an increase in both urinary flow rate and sodium excretion (Fig. 4). These changes appear to be related to the asphyxia and not caused by the saline infusion for the response quickly diminished during the recovery period. Rowe and Strauss (15) found an increase in urine flow and solute excretion during the first $60 \mathrm{~min}$ in newborn piglets breathing $10 \%$ oxygen. Other investigators have reported that the newborn infant is oliguric during prolonged periods of respiratory distress $(4,6,19)$. Possibly the increased urinary output observed early in the course of the stress is later modified by changes in total fluid and electrolyte balance as well as changes in renal hemodynamics. The increase in urinary flow rate may be related to the increase in systemic blood pressure seen during this time. However, changes in filtration fraction and/or intrarenal distribution of blood flow in these animals cannot explain the effects of stress on urine flow and sodium excretion as has been suggested for other situations $(7,20)$.

Plasma renin activity is elevated during the newborn period and then gradually decreases to adult levels (11). In spite of this 
elevation the newborn has the capability to respond promptly to stimulation of the renin-angiotensin system (17). Stimulation caused by hypovolemia, hypoxia, and disturbances in sodium concentration results in an increase plasma renin activity (13). It is unlikely that hypovolemia caused the increase in plasma renin activity found in our study (Fig. 5). All blood samples removed were replaced by equal volumes of saline immediately following their withdrawal. Hematocrit did not change significantly. It is more likely that the increase in renin concentration was mediated either through changes in renal hemodynamics or an increase in sympathetic activity (8). The elevated plasma renin concentration may have contributed to the elevated blood pressure; however, other factors including stimulation of the sympathetic nerve system or circulating catecholamines cannot be eliminated.

It is not possible to specify whether changes in $\mathrm{pO}_{2}, \mathrm{pCO}_{2}$, or a combination of both resulted in the observed changes in renal function. Recently, Daniel and James (5) pointed out that the effects of hypoxia and hypercarbia on renal function are variable. Severe and prolonged hypoxia leads to reduced renal perfusion and oliguria whereas moderate or short term episodes are followed by polyuria and increased excretion of electrolytes. The arterial $\mathrm{pCO}_{2}$ influences the response to hypoxia in that hypocapnia is associated with diuresis and hypercapnea results in a decreased renal blood flow. Additionally, Guignard et al. (9) has shown that $\mathrm{pO}_{2}$ was the same in newborns with moderate or severe impairment of renal function, suggesting factors other than arterial oxygen tension may be important. Using the piglet, Reddy et al. (14) observed an increase in renal blood flow secondary to moderate degrees of hypercapnea and acidosis and a decrease in renal blood flow with severe hypercapnea and acidosis.

Thus, while changes in $\mathrm{pO}_{2}$ and $\mathrm{pCO}_{2}$ result in a variety of responses, the present study suggests that during the early phases of asphyxia in the newborn piglet the most striking alterations occur in renal blood flow and urinary loss of fluid and electrolytes. It would appear that both the severity of the asphyxia and length of asphyxia are important factors in the effects on renal function.

\section{CONCLUSION}

The effects of hypoxia, hypercarbia, and acidosis on renal function were examined in unanesthetized piglets $6-96 \mathrm{hr}$ of age. After an increase in the respiratory dead space arterial $\mathrm{pO}_{2}$ decreased whereas $\mathrm{pCO}_{2}$ and hydrogen ion concentration increased. Glomerular filtration rate remained unchanged, but renal blood flow decreased from $186 \pm 21($ SEM) to $120 \pm 21$ $\mathrm{ml} / \mathrm{min} / \mathrm{m}^{2}$ without any changes in intrarenal distribution. Sodium excretion and urinary flow rate increased from $1.99 \pm 0.8$ to $8.1 \pm 2.5 \mu \mathrm{Eq} / \mathrm{min}$, and $5: 5 \pm 1.1$ to $10.83 \pm 2.2 \mu \mathrm{l} / \mathrm{min}$, respectively. Plasma renin concentration rose from $67 \pm 10$ to $109 \pm 14 \mathrm{ng} / \mathrm{ml}$.

\section{REFERENCES AND NOTES}

1. Allen, A. C., and Usher, R.: Renal acid excretion in infants with the respiratory distress syndrome. Pediat. Res., $5: 345$ (1971).

2. Alward, C. T., Hook, J. B., Helmrath, T. A., and Bailie, M. D.: Effects of asphyxia on cardiac output and organ blood flow in the newborn piglet (Submitted for publication).

3. Brenner, B. M., Deen, W. M., and Robertson, C. R.: Determinants of glomerular filtration rate. Ann. Rev. Physiol., 38: 9 (1976).

4. Cort, R. L.: Renal function in the respiratory distress syndrome. Acta Paediat. Scand., 51: 313 (1962).

5. Daniel, S. S., and James, L. S.: Abnormal renal function the newborn infant. J. Pediat., 88: 856 (1976).

6. Dauber, I. M., Krauss, A. N., Symchych, P. S., and Auld, P. A.: Renal failure following perinatal anoxia. J. Pediat., 88: 851 (1976).

7. Daugharty, T. M., Ueki, I. F., Nicholas, P., and Brenner, B. M.: Comparative renal effects of isoncotic and colloid-free volume expansion in the rat. Amer. J. Physiol., 222: 225 (1972).

8. Davis, J. O., and Freeman, R. H.: Mechanisms regulating renin release. Physiol. Rev., 56: 1 (1976).

9. Guignard, J. P., Torrado, A., Mazonni, S. M., and Gautier, E.: Renal function in respiratory distress syndrome. J. Pediat., 88: 845 (1976).

10. Haber, E., Koerner, T., Page, L. B., Kliman, P., and Parnode, A.: Application of a radioimmunoassay for angiotensin I to the physiologic measurements of plasma renin activity in normal human subjects. J. Clin. Endocrinol., 29: 1349 (1969).

11. Kotchen, T. A., Strickland, A. L., Rice, T. W., and Watlers, D. R.: A study of the renin-angiotensin system in newborn infants. J. Pediat., 80: 938 (1972).

12. Moore, E. S., Galvez, M. B., Paton, J. B., Fisher, D. E., and Behrman, R. E.: Effects of positive pressure ventilation on intrarenal blood flow in infant primates. Pediat. Res., 8: 792 (1974).

13. Mott, J. C.: The place of the renin-angiotensin system before and after birth. Brit. Med. Bull., 31: 44 (1975).

14. Reddy, G. D., Gootman, N., Buckley, H. M., Gootman, P. D., and Crane, L.: Regional blood flow changes in neonatal pigs in response to hypercapnea, hemorrhage, and sciatic nerve stimulation. Biol. Neonate, 25: 249 (1974).

15. Rowe, M. I., and Strauss, J.: The renal response of the newborn to hypoxia. Pediat. Res., 7: 411 (1973).

16. Siegel, S. R., Fisher, D. A., and Oh, W.: Renal function and serum aldosterone levels in infants with respiratory distress syndrome. J. Pediat., 83: 854 (1973).

17. Siegel, S. R. and Fisher, D. A.: Perturbation of the renin-angiotensinaldosterone system in the newborn lamb. Pediat. Res., 10: 149 (1976).

18. Stein, J. H., Boonjaren, S., Wilson, C. B., and Ferris, T. F.: Alterations in intrarenal blood flow distribution: Method of measurement and relationship to sodium balance. Circ. Res., 32,33 (Suppl. II): 61 (1972).

19. Torrado, A., and Guignard, J. P.: Renal failure in respiratory distress syndrome (RDS). J. Pediat., 85: 443 (1974).

20. Torrado, A., Guignard, J. P., and Gautier, E.: Hypoxemia and renal function in newborns with respiratory distress syndrome (RDS). Helv. Paediat. Acta, 29: 399 (1974).

21. This research was supported by NIH Grant HD06290 from the NICHHD. Dr. Alward was a postdoctoral fellow of the National Kidney Foundation and Kidney Foundation of Michigan. The authors wish to express their gratitude to Ms. Toni Thiel, Ms. Sara Patton, and Mr. Keith Crosslan for their technical assistance.

22. Requests for reprints should be addressed to: Michael D. Bailie, M.D., Department of Human Development, B342 Life Sciences, Michigan State University, East Lansing, MI 48824 (USA).

23. Received for publication March 4, 1977.

24. Accepted for publication June $28,1977$. 